\title{
On Validation of Concept Map as an Assessment Tool of L2 Reading Comprehension: A Triangulation Approach
}

\author{
Reza Pishghadam (Corresponding author) \\ English Department, Ferdowsi University of Mashhad \\ PO box 9177948974, Park Square, Ferdowsi University, Mashhad, Iran \\ Tel: +98-915-307-3063Ｅ-mail: rpishghadam@yahoo.com
}

\author{
Afsaneh Ghanizadeh \\ English Department, Ferdowsi University of Mashhad \\ E-mail: ghanizadehafaneh@yahoo.com
}

Received: January 30, 2010 Accepted: March 22, 2011 doi:10.5430/wjel.v1n1p80

\begin{abstract}
This study aims at addressing the issues related to reliability and validity of adoption of concept maps to assess L2 reading comprehension. To this end, this study was designed in two major phases. During the first phase, a test of reading in the form of select and fill-in concept map was designed, and its reliability (KR-21), content, concurrent (IELTS), and construct validity (using protocol analysis) were substantiated. During the second phase 300 participants were asked to take the newly-made test along with two other test formats (multiple choice and selective gapped summary) to determine which one is more correlated with L2 reading proficiency. The results demonstrated that concept map can be a reliable and valid tool of L2 reading assessment, having the potential to assess discourse comprehension and connected understanding and making reconciliation between objective discrete-point tests and integrative ones.
\end{abstract}

Keywords: L2 reading proficiency, Validation, Select and fill-in concept map, Test- taking strategies

\section{Introduction}

A concept map is a graphical node-arc representation of the relationships among a collection of concepts. They are composed of concepts, enclosed in circles or boxes, and connecting lines indicating the relationships between concepts or propositions. Interest in concept maps stems from their relationship to memory and learning theory (Novak, 1998). A prominent element of semantic memory theory is that of associative networks of knowledge. The central premise is that knowledge is stored in a network format where concepts are connected to each other. The epistemology - knowledge source and creation - of concept maps builds on the theory of learning of concept maps. It is based on human constructivism. From the learning perspective, Ausebelian's (1968) learning theory, that posits a learner attains new knowledge through a process of integrating new knowledge with existing knowledge, encompasses the psychology of concept maps. In this case, a network representation can be used to show the integration of different concepts.

Concept maps have been used for a variety of educational purposes. Researchers have used concept maps as a means for displaying information (e.g. Daley, 2004; Freeman, 2002; Jonassen, 1992; Lambiotte\&Dansereau 1992; Pankratius, 1990) and as a tool to support the design of instructional materials (Ferry, Hedberg, \& Harper, 1997; Lederman \&Latz, 1995; McDaniel, Roth, \& Miller, 2005). Others have focused on concept map construction as an instructional activity (Buzan, 1995; Carrell, 1985; Leahy, 1989; Ghanizadeh, 2007; Pishghadam\&Ghanizadeh, 2006). Still others focused on the role of concept maps in assessment (Anderson \&Haung, 1989; Kinchin, 2000; Makham, Mintzes, \& Jones, 1994; Novak \&Masunda, 1991; Reese, 2004; Turns, Atman, \& Adams, 2000). Although concept maps have been used extensively as assessment tools in science education over 25-30 years (Schau, et al., 2001; Ruiz-Primo, 2000), certain questions about reliability and validity of concept maps persist today. These issues pivot extensively around the scoring of concept maps. To resolve the problem, a variety of methods for scoring concept maps have been presented thus far. Novak and Gowin (1984) were among the first researchers who provided a quite elaborate scoring system based on correcting linkage, number of levels of hierarchy, and the number of crosslinks, as it may be called "proposition accuracy score” (Ruiz-Primo, 2000). The framework they proposed was based on these four scoring components: 1) score all valid relationships; 2) count the number of valid hierarchical levels; 3 ) score valid cross-links at three times the 
value of the hierarchical level; 4) score each valid example. Following Novak's scoring rubric, Reese (2004) made some modifications regarding the weighting of the concept map attributes and concluded that propositions and cross-links are much more sensitive to differences between high and low achievement than levels or branches.

However, the diversity and range of students' self-constructed maps even on a very specific subject in a domain burdened these scoring systems with serious practical difficulties. As a reaction to this shortcoming, others used a criterion map technique or "convergence score" (Ruiz-Primo, 2000), as a foundation for evaluating the students' constructed maps. Still, this scoring system could not sufficiently obviate the aforementioned deficiencies. The disadvantages, in effect, persist when the assumptions of developing a criterion or expert map are not fully met. The assumptions, according to Ruiz-Primo (2000), are: 1) there is some agreed-upon organization; 2) experts in that domain can agree on the structure; 3) experts' concept maps provide a reasonable representation of the subject domain.

Another possible solution for these scoring difficulties, according to Yin et al., (2004) was to ask students to construct a map selecting from predetermined linking phrases. A potential advantage of this technique was that the scoring of these maps could be automated with computers (O'Neil et al., 1991; Klein et al., 2001, cited in Yin et al., 2004). However, Ghaye and Robinson (1989) interpreted maps that exhibited a close match with the predetermined structure as being indicative of a 'passive and reproductive' learning posture or as the case of 'transmission teaching' and 'absorption learning' rather than a meaningful learning approach as described by Novak and Gowin (1984).

In another attempt, Ruiz-Primo and Shavelson (1996) provided a comprehensive analysis of scoring systems, employing multiple scoring systems for a single concept map task. Similarly, McClure, Snoak, and Suen (1999) devised six scoring methods for a single map including: a) holistic, b) holistic with master map, c) relational, d) relational with master map, e) structural, f) structural with master map.

Another, rarely explored, concept map scoring format uses fill-in maps with or without alternatives. Keeping the test designers concept map intact, some of the concept words or linking phrases are omitted, so that students are required to generate the words or select from a set of alternatives (called select and fill in or SAFI). The following figures depict examples of fill-in-maps (See Figure 1).According to Schau, Mattern, Zelik, Teague, and Weber (2001), Surber (1984) may have been the first to use the fill-in concept map format as an assessment approach. Yet, a review of the literature reveals that this approach was not initially welcomed. More recently, Schua's studies (1997\& 2001) brought it into favor in that in all the experiments, the scores of SAFI were strongly correlated with those of the standardized multiple choice test. Furthermore, the scores of SAFI exhibited a considerable relationship with the scores of generated concept maps. $\mathrm{He}$, accordingly, proposed this technique as a valid and reliable measurement of students' connected understanding of science. Schua's compelling argument in favor of SAFI is that asking students to draw a map from scratch imposes too high a cognitive demand to produce a meaningful representation of their knowledge, whereas SAFI concept map has the potential to overcome this limitation associated with generated concept maps.

Upon fully scrutinizing all concept map formats and the corresponding scoring procedures, as well as comprehensively taking into account the additional constraints imposed by having adopted an L1 instance to L2, the researchers decided to employ this alternative assessment technique, SAFI concept map,to take advantage of both integrative and discretepoint kinds of tests. Integrative in that it has potential for integrating the reading into answering questions at different conceptual levels, that is, fact, inference, vocabulary and so on. Discrete-point from this perspective that it allows for holding the psychometric view of testing by which all the items can be scored objectively. Although concept maps, whichever procedure and format they employ, have been widely used in assessing science concepts or outcomes, no research, to the best of the researchers' knowledge, has ever been conducted to employ the potential benefits of concept maps in assessing comprehension of L2 reading passages. This dearth of research echoes a clear need to accommodate such a techniquein L2 contexts along with making the required modifications.

\section{Purpose of the study}

Since designing reliable and valid scales in language education is a necessity (Pishghadam, Modarresi, 2008; Navidinia, 2010), this study is to investigate issues related to the adoption of concept maps to assess L2 reading comprehension. To this end, these questions were addressed:

1) Is SAFI concept map a valid tool to assess L2 reading comprehension?

2) Among different test formats-- multiple-choice (MC), selective gapped summary (GS), and SAFIconcept map (CM) -- is CM the most correlated one with L2 reading proficiency?

\section{Method}

This study was designed in two major phases. The first phase included an array of different steps to validate the SAFI 
concept map test of L2 reading through pilot study. This phase commenced by designing and revising the test, and proceeded by administrating the test and determining reliability and validity, accordingly. The second phase utilized the validated SAFI concept map test, along with two other prevalent reading test formats as the basis of a triplex comparison with L2 reading proficiency.

\subsection{Participants}

The participants of the main stage of phase 1 comprised eighty five upper- intermediate and advanced EFL students and teachers. Forty of the subjects were studying English in two English institutes in Mashad: Marefat and Kish. Among them, twenty five were certificate of advanced English (CAE) and fifteen were first certificate in English (FCE) students. Twenty-five other subjects were international English language testing service (IELTS) candidates from three other institutes in Mashad who had formerly registered for the test. The remaining 20 subjects consisted of the teachers of the two mentioned institutes who voluntarily and kindly participated in the study. The procedure section delineates the profile of the teachers in more detail.

The participants of the second phase were 300 junior and senior university students. They were studying eitherEnglish literature, English translation, or English teaching as their majors atFerdowsi, Imam Reza, and Azad universities.

The participants of the think-aloud procedure were 8 upper-intermediate and advanced EFL students, 2 and 6 respectively.

Measures taken to motivate the test-takers and to justify test-taking were as follows:

1) At the outset of test administration, they were briefed on the purpose and the procedure of the study.

2) With the kind cooperation of the professors of each class, the test-takers were announced that the test results would be part of the term evaluation process.

3) The testers were pre-announced that their scores would be reported within one week after test-taking and that the confidentiality and anonymity considerations would be observed.

There is one further matter that needs to be mentioned at this point: the participants of the second phase were university students majoring in English. Given that the pilot phase was being conducted during summer and there was no access to the university students, it was carried out with English institute students and teachers. Care, however, was taken that the pilot group be similar to the target groupwith regard to their years of studying English and their proficiency level.

\subsection{Instrumentation}

Due to the nature of the present study—language testing - a number of instruments were utilized:

1) A validated SAFI concept map of L2 reading, the passages of which (three passages) were extracted from IELTS academic reading (2003);

2) The reading module of 2005 academic IELTS (comprised of three passages), as the criterion test;

3) The multiple-choice version of 2003 IELTS academic reading;

4) The selective gapped summary version of 2003 IELTS academic reading;

5) The reading module of ETS TOEFL (2005) (comprised of five passages) as the criterion test.

\subsection{Procedure}

\subsubsection{Phase 1: pilot study}

The first phase of the present study was allotted to the pilot study, undertaken in two stages. During stage 1, the original version of the test was designed; after the required refinement and modifications were made, the final version of the test was obtained. During the second stage the reliability and validity of the test were determined. The reliability was computed through K-R21. The validity was assessed via content relevance, criterion relatedness, and meaningfulness of construct.

\subsubsection{First pilot stage}

1) Devising the generative fill-in concept map test

The original version of the test was designed based on the operational definition of concept map assessment tool. To this end, the test designers condensed each reading passage-taken form 2003 IELTS academic reading- into two or three paragraphs. They, then, extracted the main ideas or concepts of the passage in form of words or phrases, and put them in squares. The squares were then connected together by arrows based on the relationships embedded in the passage. To specify the kind of relationship, the arrows were labeled by linking phrases or words. The result was a concept map 
summarizing the passage by bolding the main ideas and the relationship between them. To alter the generated concept map to a fill-in format, the test developers deleted some of the concepts or linking phrases to be provided by the testers.

2) Administering the generative fill-in concept map format

The generative fill-in concept map format was administered to the first pilot group during the summer of 2007. They were thirty eight upper-intermediate and advanced students studying at an English institute in Mashhad. They were required to read the three passages of reading module of 2003 academic IELTS and fill in the unlabeled nodes or links of each concept map. The impetus of undertaking this stage was eliciting the possible inappropriate responses for each item to be tentatively included as the probable distracters of SAFI concept map. In terms of familiarity with test format, through a briefing session, the subjects were initiated to concept mapping.

\section{3) Designing the SAFI concept map test}

Having utilized the probable distracters obtained through the administration of generative fill-in concept map of the three passages, along with the ones provided by the test developers, the researchers designed the SAFI concept map format which listed a set of alternatives for each unlabeled square or link to select from.

The profile of the test was as follows: each passage was followed by a SAFI concept map test. Each test commenced by specific instruction on how to handle the task. The instruction included the procedure of responding to the items (select the best option, marking on answer sheet), the procedure of task specification (read the whole passage first, start from the central idea...), the order in which they were to be completed (proceed in the order of the numbered squares....), and the allotted time. The instruction was followed by the corresponding computer-created concept map of the passage. The software employed to draw each map was C-map tools version 4.09 designed by Institute for human and machine cognition. Right after each map, the alternatives of every individual item were provided.

4) Administrating SAFI concept map format

Once the SAFI concept map version was designed, it was piloted with thirty other upper-intermediate and advanced EFL testers for item analysis purposes and in order to prune the test items in favor of a more homogenous test. Like the previous stage, the testers were already familiarized with concept mapping, and they sat the test under identical situations as the first pilot. The test was comprised of 42 items: 13 items for the first paragraph, 15 items for the second paragraph, and 14 items for the third paragraph. Having scored the test, the researchers investigated each individual item using item format analysis, item facility analysis, item discrimination analysis, and distracter analysis.

Modifications in the final test based on this pilot stage, particularly item facility and item discrimination results, are described in the following respective sections. Here it suffices to mention that as a result of this stage several items were discarded or revised. In a nutshell, it yielded a test comprised of 31 items: 10 items for the first passage, 12 items for the second passage, and 9 items for the third passage (See Appendix).

\subsubsection{Second pilot stage}

The final version of the test was administered concurrently with the IELTS academic reading (2005), as the criterion test. This stage was to encompass reliability, concurrent validity, and construct validity.

This stage was carried out by eighty five participants. Forty subjects were the researchers' students, studying English in two English institutes in Mashad, Marefat and Kish. Twenty-five of them were doing CAE courses and fifty were FCE students. In this case, thus, they can be classified as upper-intermediate and advanced EFL students. They were already familiar with cluster diagramming as a prewriting activity and concept mapping as a postreading strategy. To undermine the motivational aspects associated with most test taking instances, the researchers ascertained the testers that the test results would be part of the term evaluation process.

Twenty-five other subjects were IELTS candidates from three other institutes. They had been informed of the test administration via anannouncement installed on the institute boards. It explicitly stated the purpose of the test, specification of the test including the number of passages, the allotted time for each module, the actual administration date of each IELTS test, the score report procedure and date, as well as the time and place of test registration and administration. Till two days before the test, twenty eight subjects registered, but twenty five showed up for the test.

Twenty other subjects consisted of the teachers of the two aforementioned institutes who voluntarily stated their propensity to participate in the test. Among them, ten had been teaching English at intermediate levels for at least two years, six were advanced English teachers with at least two to five years experience, and four were elementary level teachers with at least one year experience. Regarding course of study, eight were undergraduate English students, four of them held or were studying towards an English MA degree, and the rest were from different fieldsof study(such as science and engineering), but were duly qualified to teach it. 
The last two groups of the candidates were kindly requested to be present 45 minutes before the test to be briefed on the concept map test format. To do so, the researchers elaborated concisely on concept mapping and how to approach the nodes and linking phrases, via Microsoft PowerPoint.

All the testers sat for two IELTS reading modules concurrently at a single session. One module was the 2003 IELTS academic reading with SAFI concept map questions. The other was the 2005 IELTS academic reading as the standard criterion test. Each module was comprised of three passages, the test format of which included true/false/not given, banked gap filling, multiple-choice, and matching headings with corresponding paragraphs. The allotted time for each module was the ILETS standard time: one hour respectively. To reduce the possible fluctuation of order effect, the order of administration was counterbalanced, i.e., half of the testers were first given the SAFI concept map format and then the IELTS criterion test, while the other half were first administered the criterion test and the SAFI concept map format second.

The rationale of utilizing IELTS academic reading in this study, and not TOEFL as it is frequently practiced in reading assessment procedures is compatible with the Cohen and Upton's (2006) contention that text length and text types are important considerations in the assessment of reading comprehension. It is presumed that longer texts exert more of discourse-level aspects and they better represent the academic experiences of students in the test design. IELTS adopts fewer longer passages in comparison with TOEFL with a greater number of shorter passages. With regard to text type, academic IELTS, as the name suggests, is the reflective of the university life and the type of reading tasks students are expected to do in academic settings. While the TOEFL passages "consisted primarily of a particular type of expository texts in which a number of discrete facts are loosely integrated and developed" (ETS, 2003, p. 1). In a nutshell, the stipulation of this study is that manipulation of reading text must be in harmony with corresponding test format in the light of text length and text type.

1) Validity

a. Concurrent criterion-related validity

To address concurrent validity, the correlation coefficient of the two sets of scores-SAFI concept map version of 2003 IELTS academic reading-- along with its counterpart 2005 IELTS academic reading, was computed through Pearson Product- Moment formula.

\section{b. Content validity}

Content validity was investigated by requesting two L2 testing specialists to check the test and comment on it. They examined the concept map, the items, and the alternatives. They were, then, provided with a sorting scale on item content congruence and applicability and a checklist on content analysis, adopted from Brown (1996). One of the informants emphasized that students be introduced to and familiarized with the test format prior to administration. As evident in the preceding sections, the recommendation was observed prior to each SAFI concept map administration.

\section{c. Construct validity}

In this study, construct validity-verifying whether the test actually measures aspects of behavior under consideration-was determined through the process-oriented approach of think aloud. The validity question, thus, pivoted around soliciting testers' test taking strategies of SAFI concept map. The impetus of employing think aloud procedure to accomplish this end is in line with plethora of recent studies (e.g. Green, 1998; Cohen, 1998). In this respect, particularly illuminating is to contemplate Green's (1999) words that "verbal protocols are increasingly playing a vital role in the validation of assessment instruments and methods [in that they] offer a means for more directly gathering evidence that supports judgments regarding validity than some of the other more quantitative methods” (p. 3).

Since this study, as the first endeavor in the testing and reading literature, applied concept mapping as a testing technique of L2 reading comprehension, and accordingly as the first study to explore the corresponding test taking strategies, a multi-method approach of both introspection and retrospection interviews was adopted not only for the sake of lucid perception and exploration of strategies unique to concept map test format, but also to undermine the pitfalls associated with either approach.

The validation procedurewas conducted on eight upper intermediate and advanced Iranian EFL learners in separate sessions. An array of steps was utilized during data collection procedure. At the outset, the participants were informed about the objective and procedure of the study. As the second step, they were coherently briefed on what exactly they were supposed to do along with some practice tasks to familiarize them with the procedure. They were, then, presented with the test and were asked to think aloud while reading the passage and answering the test items. The protocols were recorded for subsequent analysis. Once the sets of protocols were collected, they were transcribed word by word. 
Following Green's (1998) guidelines, protocols were transcribed exactly as they were, i.e., they were not modified or tidied up by adding or substituting words, or by altering verbalization. The transcription was, then, segmented by every single process. Depending on the nature of each process at work, the segments, thus, ranged from a single phrase to a cluster of sentences. Below is an extract from some instances of verbal protocol which have been segmented. Each / delineates a segment and denotes pauses in speech.

1. According to the text " As the world continues to increase in complexity, university graduates will need to be equipped to cope with rapid changes in technology and to enter careers that may not yet be envisaged with change of profession being commonplace”.

2. Well........let's read the previous paragraph again.

\section{As the map shows item 10 is connected to item 12. /}

After the protocol was segmented, the researcher went through the transcription several times to extract the recurring features. To avoid forging the protocol into a particular model or pre-existing framework, the coding scheme was devised by focusing on heeded information contained within the protocol. To highlight tentative problems and errors in the coding process, a subset of the data was examined by a specialist in the field. Based on the researchers' preliminary inspection and the specialist's recommendation, the final coding system was formulated. In order to make the scheme more specific to concept map test format and accordingly more manageable and concise, those strategies reckoned virtually indispensable to almost every comprehension process, such as paraphrasing, rereading, solving vocabulary problems, were not included in the final paradigm.

The second phase of the present study utilized the SAFI concept map test in conjunction with two other test formats, namely: multiple choice and selective gapped summary. The main objective of this phase was a triple-comparison among the scores on SAFI concept map (CM), multiple choice (MC), and selective gapped summary (GS) - three formats of assessing L2 reading comprehension - to determine which one is more correlated with testers' L2 reading proficiency, and hence is a better indicator of comprehension. So, here the variable is, indeed, the test format. Something should be stated at this point about the twofold rationale of infusing this phase: although the main objective of this phase is to examine the effect of test format, it can also be used to further validate the test.

Unlike preceding phase, the testers of this stage were all at the same reading proficiency level. The employment of the two aforementioned testing formats was based on the premise that each shares certain characteristics with SAFI concept map format and are distinct in some other ways. The multiple choice format shares the selective and psychometric property, and is different from the perspective of discrete-point characteristics. The selective gapped summary is identical to SAFI concept map in that they are both selective and integrative, and in that the items are connected, while the SAFI concept map has the extra property of visual representation.

To design multiple choice and selective gapped summary tests, the researchers utilized the items and options of validated SAFI concept map, but adopted different formats (multiple choice and gapped summary).

To conduct this phase, the three different test formats of the same passages (2003 IELTS academic reading) were concurrently administered with standard reading test to three different groups. Unlike the first phase of this study, the researchers decided to employ the reading module of TOEFL (ETS, 2005) as the criterion test in lieu of academic IELTS on the premise that reading module of TOEFL is less demanding and considering the fact that the cross administration of two tests adds the element of challenge. As stated earlier, since the main purpose of this phase was to figure out which test format was more correlated with L2 reading proficiency, it was mandated that all the testers be at the same level of reading proficiency. However, it was not practical to administer the standard test and the test under study in two distinct sessions. Consequently, it was decided to administer the two tests concurrently to all testers regardless of their proficiency level, and then to examine the assumption of equal proficiency level via ANOVA.

The participants of this phase were three hundred university English students majoring in English literature, teaching or translation, and studying at different academic terms. Since the testers were of different universities: Ferdowsi, Azad, and Imam Reza, and in different terms and classes, it was not feasible to hold the tests in a single session, but class by class. Yet, endeavor was made to maintain the testing environment as uniform as possible across all the administrations. One hundred and five of the subjects took SAFI concept map test (CM), ninety eight took multiple choice (MC), and nighty seven took selective gapped summary (GS), along with the criterion test. The applied procedure was identical to that of the pilot phase. 


\section{Results}

\subsection{Results of the first phase}

\subsubsection{The final version of SAFI concept map test}

As illustrated in the previous section, to design, develop, and revise the SAFI concept map test of L2 reading comprehension, an array of steps was followed. These steps yielded a test comprised of 34 items: 11 items for the first passage, 12 items for the second passage, and 11 items for the third passage. As stated in the method section, the original version of the test was made of 42 items: 13 items for the first passage, 15 items for the second passage, and 14 items for the third passage. Using item facility and discrimination analysis, the researchers retained the items with a facility index between 0.2 and 0.85 and with a discrimination index of higher than 0.25 . Seven items were discarded and four items were revised. The types of discarded items were network association and linking phrases. Network association is a relationship between two concepts that are not derived from the same node. The revised items were at the level of rewriting alternatives.

\subsubsection{Reliability}

Scores from the second pilot stage were submitted to an internal consistency estimate. The data were analyzed through Kuder-Richardson 21 reliability coefficient. Employing means and standard deviation of scores ( $\mathrm{X}=19.1, \mathrm{SD}=5.1)$, and applying KR-21 formula, the reliability coefficient was computed as 0.71 .

The results, in effect, substantiate that SAFI concept mapping can be a reliable tool of L2 reading assessment, the stipulation of which is the moderately high degree of go- togetherness of the items of SAFI test.

\subsubsection{Validity}

\subsubsection{Concurrent criterion-relatedness validity}

Concurrent validity was investigated by considering the degree of go-togetherness of scores on SAFI concept map, with scores on IELTS academic reading (2005) through Pearson Product Moment Correlation Coefficient. It was found that the scores on SAFI concept map were correlated at approximately $r_{=} .90$ with the scores on standard test. In other words, the magnitude shows a strong correlation.

\subsubsection{Construct validity}

The participants' verbalizations yielded the following strategies, depicted in Table 1 (See Table 1).

\subsection{Results of the second phase}

As already stated, the assumption of this phase was that the three groups were equal in terms of L2 reading proficiency. Table 2 presents summary descriptive statistics of the criterion measures in each group (See Table 2).

Although the means and standard deviations of the scores on the criterion measure revealed slight differences among the groups, in order to further underpin the assumption of testers' equal proficiency level based on the procedure stated in method section, Analysis of Variance (ANOVA) was employed to check the assumption of equal L2 reading proficiency level. As indicated in the following table, the results of ANOVA did not reveal the differences to be significant $(\mathrm{F}=$ 4.073, $\mathrm{p}<.05$ ) (See Table 3).

The correlation coefficient of CM was computed as $(r=.63$, p< 0.05), MC ( $r=.68, p<0.05)$, and GS $(r=.52, p<0.05)$. The results, in effect, revealed that among the three test formats, MC was the highest correlated one with testers' L2 reading proficiency. With a slight difference, CM was the second correlated one with L2 reading proficiency, and GS the last one. The next section will pinpoint the factors that aided the magnitude of correlation in MC group.

\section{Discussion}

\subsection{Discussion of the first phase}

As indicated in the previous section, SAFI concept map can be a valid and reliable technique in assessing L2 reading. The high correlation between the concept map test and the standard test entails that this testing technique is a valid measure of assessing L2 reading comprehension as IELTS testing techniques are. Of course, the researchers are aware that, if at all possible, the degree of correlation should be interpreted in the light of evidence from construct validation, as Bachman (1990) contended.

As far as comprehension and test taking process are concerned, a careful examination of each participant's protocols and accordingly each strategy use yielded the following discussion. They revealed that participants used different starting points: four testers skimmed the passage quickly to form the general impression, three testers first surveyed the map and then read the passage, and one tester first surveyed a section of the passage, then a segment of the map and the 
alternatives. Regarding the second strategy, concept formation, all testers used this strategy in answering every individual item. To do so, they looked at the map and identified the concept enclosed in box. Proposition formation was also used by all testers, for all the items. In order to answer each item (each gapped box), they had to use the map, link two concepts in the concept map via linking phrases, and form a proposition. An instance of this strategy use is as follows: "I look at the box 'spider silk' and I read the connecting line 'can be synthesized' as 'spider silk can be synthesized' ". Another strategy all testers utilized to answer each item was proposition synthesizing, i.e., linking identified propositions. For instance, in order to answer item 3 of the first passage, testers used the already identified proposition 'spider silk is extremely strong', used the linking phrase ' may have application in ' and box 3.

What has emerged so far from the use of abovementioned strategies reveals that in order to answer the items, the testers had to identify concepts, link them to form propositions, and then link propositions to form the text structure. Testers' verbalizations also revealed that the map helped them visualize and conceptualize the organization of the text, as is evident in this example: "from the concept map, I get that the reading is about the causes and consequences of global warming". The sixth strategy, gist locating, was used at least once by all testers. Like previous strategies, this one was used in conjunction with the map, i.e., they identified the main idea, distinguished between salient and subsidiary points by matching the concepts expressed in concept map, as the main points, with the corresponding ideas in the text. This can be seen in the following protocol: "Items 10, 11, and 12, all are derivated from the higher square 'assessment'. So I search the section or paragraph about assessment to find the answer". Somehow related to the previous strategy is redundant idea skipping. Since all items to be answered were specified in the map, and since each individual item was derived from a hierarchical concept, testers' decision upon irrelevant material in the text was facilitated; irrelevant from the perspective that they could complete the test without referring to that specific portion. Testers' verbalizations suggested that they did so, on the grounds that the deemed the concepts and relations designated in the map as foci of the text and the items, as is evident in the following instance: "the section (F) I'm reading (about how to measure sea-level rising or falling) does not seem necessary in completing the map, since nothing has been mentioned in the map. So I skip it". However, this strategy was used by 6 testers, and two of them tended not to miss any section even if it was not included in the map. Among those who used this strategy, two of them used it only once in each passage, and the rest used it more than once. The eighth strategy, inference-making, was used to find the answer of items based on information not explicitly stated in the text. The protocols suggested that the use of this strategy was not dependant on a property in concept map, but on the nature of the item. Therefore, unlike the previous strategies, the map did not seem to play a distinctive facilitative role in answering such items. The ninth strategy, backtracking, was not also directly associated with any specific feature in concept map, although the visual property of concept map aided testers to locate information. All testers reported the use of backtracking several times. The last two strategies, correct response selection via other alternatives, and correct response selection via clues I other items, were mostly associated with the selective nature of the test. Two testers used these strategies for two or three items in each passage. Five testers used them in answering one or two items in each passage. While one tester did not use them in the second passage, but used them twice in the first, and once in the third passage.

As far as comprehension and test taking process are concerned, however, a lucid comparison between the traditional approaches and concept mapping elucidates an array of advantages pertaining to concept mapping assessment technique. The two key advantages amount to testers' utilization of connected understanding and discourse comprehension, as well as visual representation property of concept mapping when completing the test. Testers' verbalization suggested that virtually all subjects used concept identification, proposition formation, and proposition association as manifestation of connected understanding and discourse comprehension; and gist locating, text structure identification, and redundant idea skipping as exploiting visual property of concept maps.

In order to categorize the yielded strategies, the researchers reviewed and reconsidered the strategies.In effect, all the identified strategies may be subsumed under broader classifications: lower-order processing strategies, higher-order processing strategies, and test-wiseness strategies, as depicted in the following table. The dichotomy of lower-order and higher-order strategies were taken from Ghonsooli's (1997) classification of reading strategies, to which the testwiseness strategies were added to capture those strategies dependant on test takers' knowledge of how to take selective tests. Ghonsooli's recommendations also pertained to classifying the strategies under each hierarchical category to ensure the soundness and integrity of classification. The following table depicts this hierarchical classification along with frequency counts (See Table 4).

As the table demonstrates, more strategies are weighed toward higher-order strategies both from the perspective of strategy type (three strategies were subsumed under lower-order, six under higher-order strategies, and two under testwiseness strategies), and frequency counts (180 out of 536 were allotted to lower-order, 337 to higher-order, and 19 to test-wiseness strategies). All in all, what emerges from the above discussion, effectively substantiates the contention that 
concept map is inherently applicable to the measurement of higher-order conceptual understanding that characterizes meaningful learning.

\subsection{Discussion of the second phase}

The results of the second phase of the present study verify the abovementioned discussion about the viability of concept map to assess connected understanding and to visually represent the text structure. As already stated, having kept all the variables homogeneous-including testers' proficiency level, reading passage, test items, number of items, degree of objectivity in scoring, and allotted time-the study examined the two already obtained advantages of concept mapping-assessing connected understanding and visual representation-through different test formats. Via MC, the integrative nature of CM to assess connected understanding was checked, while the visual property was investigated via the integrative test of selective GS.

Although among the three test formats which were used in this study, MC was shown to be the highest correlated one with the testers' L2 reading proficiency, the degree of difference seems negligible, especially when considering the two potential factors that did aid the magnitude of correlation in MC group: one is that, due to the ubiquitous nature of MC test format, the testers were undoubtedly better familiar with this format, and this might alternatively affect their performance. The second is embedded in the undeniable yet salient fact that MC was being correlated with a homogenous counterpart, i.e., multiple-choice, and this would inherently increase the magnitude of correlation.

Aside from internal comparison, a cross comparison between these test formats yields tenable discussions. Comparing $\mathrm{CM}$ with MC format, one can delicately detect the discernible trace of discourse comprehension and connected understanding. Concerning the second comparison-GS with MC—although both are integrative and encompass connected understanding, the results pinpoint the additional property of visual representation exerted by CM.

The researchers interpret these findings to mean that CM and MC tests measure overlapping and yet somewhat different aspects of L2 reading comprehension. Findings of the present phase also verify the researchers' contention that SAFI CM makes reconciliation between objective discrete-point tests and integrative ones by obviating the drawbacks associated with either approach, while making use of their potential advantages.

Since the results of this study provide initial evidence of the validity of SAFI concept map as an assessment tool of L2 reading comprehension, further research is needed to capture the predictive and consequential validity of concept map test format. Also given that this study is the first endeavor in the literature that employed concept mapping as L2 reading assessment technique, it can be deemed as a prelude to initiate other studies. Undoubtedly, the research agenda in this area is long, yet essential, if we want to explore the broad aspects and issues pertaining to concept mapping assessment technique.

\section{Conclusions}

To sum up, the SAFI concept map as an L2 reading assessment tool exerts an array of advantages which justifies incorporating concept mapping as a valuable component of L2 reading assessment tool box. First, the testers' protocol analysis substantiates that concept maps have the potential of assessing connected understanding and discourse comprehension, two features almost absent in ubiquitous test methods such as multiple choice. Second, the visual property of concept maps has a facilitative role in completing the test; this feature is also missing in most prevalent test methods. Third, concept map is definitely capable of assessing higher-order abilities, such as inference-making and text structure identification. Fourth, practically speaking, the comparison of degree of objectivity and the time required to score SAFI concept map with that of other integrative tests as cloze or short answer would favor the former. Fifth, there is an increasing common practice of referring to concept maps as "alternative assessment" (Collins, 1993; Ruiz-primo \&Shavelson, 1996; Shavelson, Lang \&Lewin, 1993). If this is the case, it perpetuates the perception that concept maps measure more complex levels of thinking, as well as more authentic aspects.

The findings also substantiate the contention that among prevailing theories of reading, concept mapping can be well situated within the framework of constructivist theory. This theory posited that meaning construction is accomplished in three ways: by organizing the context according to the text structure, by selecting context on the basis of saliency and importance of ideas, and by connecting context through inference making and elaborations (Spivey \& Mellon, 1989). Given what was yielded through construct validation process, it can be concluded that the same also goes for reading assessment. The first aspect of constructivism-organization-is manifested through concept identification and text structure identification. The second aspect—selection—can be pinpointed through gist locating and redundant idea skipping. The constructive element of connection is evident in proposition formation and proposition synthesizing.

Hopefully, the findings of the present research purport the prospect of inclusion of concept mapping as a tool of measuring higher-order L2 reading abilities, not only by the test developers, but also by the instructors within their own 
class settings. Indeed, there is nothing written in stone that says multiple choice tests must be used to test L2 reading comprehension at all levels and all testing settings form achievement to proficiency ones. The question, however, remains about the stimulation of such innovative practices: whether as a classroom practice induced by teacher or as a proficiency or placement test administered by test developers. As Canas and Novak (2006) maintained this is a chicken-and-egg problem because concept maps cannot be required on national achievement tests if most students have not been given to learn to use this facilitative tool. On the other hand, if national exams would begin to include concept maps as a segment of the exam, there would be a great incentive for teachers to teach students how to use this tool.

The participants of the first and second phases of this study comprised eighty two and three hundred upper intermediate and advanced EFL students, respectively. Undoubtedly, within this group there might be subgroups that differ in individual characteristics, such as background knowledge, unfamiliarity with test method, field independence, motivation, visual orientation, age, gender, and so on. The major limitation of this study is reflected in the dearth of control over these factors. Another limitation embedded in the fact stated by Brown (1996) and Bachman (1990) that construct validation will be most promising and convincing if it is a cumulative process of gathering evidence based on a variety of approaches, such as differential-group studies, protocol analysis, and multi trait-multi method design. Yet, it was not possible within the scope of this research to integrate all of these approaches in determining construct validity.

Needless to say, the results of the present study should be interpreted cautiously. Since in many ways, this research is a first of its kind, additional studies are needed to replicate and stabilize the results and to accommodate more testers and more variables.

\section{References}

Ausuble, D.P. (1968). Educational psychology: A cognitive view. New York: Holt.

Anderson, T., \& Huang, S. C. C. (1989). On using concept maps to assess the comprehension effects of reading expository text (Tech. Rep. No. 483). Cambridge, MA: Center for the Study of Reading. (ERIC Document Reproduction Service No.ED 310 368).

Bachman, L.F. (1990). Fundamental considerations in language testing.Oxford: Oxford University Press.

Brown, J. D. (1996). Testing in language programs.New Jersey: Prentice Hall Regents.

Buzan, T. (1995).The mindmap book. ( $2^{\text {nd }}$ ed). London, UK: BBC Books.

Cañas.A.J., \& Novak J.D. (2006). Concept Maps: Theory, methodology, technology. Proceeding of the second international conference on concept mapping. San José, Costa Rica.

Carrell, P. L. (1985).Facilitating ESL reading by teaching text structure.TESOL Quarterly, 19 (4), 727-52.doi:10.2307/3586673, http://dx.doi.org/10.2307/3586673.

Cohen, A. D., \& Upton, T. A. (2006). Strategies in responding to the new TOEFL reading tasks.TOFLE monograph series 33.

Collins, A. (1993). Issues in assessment: Purpose, alternative assessment and equity. School of Education Review, 5, 68-77. (ERIC Document Reproduction Service No. 370 771)

Daley, B. J. (2004). Using concept maps in qualitative research.Proceeding of the first internationalconference on concept mapping. Pamplona, Spain.

ETS. (2003). Task specifications for Next Generation TOEFL reading test.Unpublished manuscript.

Freeman, L.A., (2004). The power and benefits of concept mapping: Measuring use, usefulness, ease of use, and satisfaction.The proceedings of the First International Conference on ConceptMapping.Pamplona, Spain.

Ferry, B., Hedberg, J., \& Harper, B. (1997). How do preservice teachers use concept maps to organize their curriculum content knowledge.SCILITE, 97.23-56.

Ghanizadeh, A. (2007). On the impact of concept mapping on EFL learners' reading comprehension.Paper presented in the forth conference on issues in language teaching in Iran. Tehran University.Ghaye, A. L., \& Robinson, E. G. (1989) Concept maps and children's thinking: a constructivist approach. In Slater, F. (Ed): Language and learning in the teaching of geography (pp. 115-139). London: Routledge.

Ghonsooli, B. (1997). Introspection as a method of identifying and describing competence in reading skills. Unpublished PhD Thesis. 
Glynn, S. (1997) Drawing mental models. Science Teacher, 64(1), 30-32.

Green, A. (1998). Verbal protocol analysis in language testing research: A handbook.Cambridge: Cambridge University press.

Hening, G. (1999). A guide to language testing: Development, evaluation, research. Cambridge: Newbury house publication.

Kinchin, I. M. (2000).Using concept maps to reveal understanding: a two tier analysis.School Science Review, 81, 41-46.

Klein, D.C.D., Chung, G.K.W.K., Osmundson, E., Herl, H.E., \& O’Neil, H.F. (2001). Examining the validity of knowledge mapping as a measure of elementary students' scientific understanding. Los Angeles: National Center for Research on Evaluation, Standards, and Student Testing (CRESST).

Jonassen, D.H. (1992). Concept mapping and other formalisms as mindtools for representing knowledge.Retrieved Jun 2006 from http://www.Icbl.Hw.ac.uk./projects/granum/aitdocs/dav alt. htm.

Lambiotte, J.G, \&Dansereau, D. (1992). Effects of knowledge maps and prior knowledge on recall of science lecture content. Journal of Experimental Education,60(3), 189-201.doi:10.1080/00220973.1992.9943875, http://dx.doi.org/10.1080/00220973.1992.9943875.

Leahy, R. (1989). Concept mapping: Developing guides to literature. College Teaching, 37(2), 62-69. doi:10.1080/87567555.1989.9925480, http://dx.doi.org/10.1080/87567555.1989.9925480

Lederman, N. G., \&Latz, M. S. (1995). Knowledge structures in the preservice teacher: Sources, development, interactions, and relationships to teaching. Journal of Science Teacher Education, 6(1), 1-19. doi:10.1007/BF02614542, http://dx.doi.org/10.1007/BF02614542.

Markham, K., Mintzes, J., \& Jones, G. (1994). The concept map as a research and evaluation tool: Further evidence of validity. Journal of Research in Science Teaching, 31, 91-101. doi:10.1002/tea.3660310109, http://dx.doi.org/10.1002/tea.3660310109.

McClure, J. R., Sonak, B., \&Suen, H. K. (1999) Concept map assessment of classroom learning: reliability, validity and logistical practicality. Journal of Research in Science Teaching,36(4), 475-492.McDaniel, E., Roth, B., \& Miller, M. (2005).Concept mapping as a tool for curriculum design.Issues in informing science and information technology,4, 504-511.Messick, S. A. (1975) The standard problem: meaning and values in measurement and evaluation. American psychologist, 30, 955-66.Navidinia, H. (2010). SLA research in postmethod: Neglects, misunderstandings, and alternatives. International Journal of Language Studies, 4, 139-152.

Novak, J., \&Gowin, B. D. (1984). Learning how to learn. New York: Cambridge University Press.Novak, J.D., \& Musonda, D. (1991). A twelve-year longitudinal study of science concept learning. American Educational Research Journal, 28, 117-153.

Novak, J. D. (1998). Learning, creating, and using knowledge: Concept maps as facilitative tools in schools and corporations. Mahweh, NJ: Lawrence Erlbaum Association.

Novak, J. D. (1998). Learning, creating, and using knowledge: Concept maps as facilitative tools in schools and corporations. Mahweh, NJ: Lawrence Erlbaum Association.

O’Neil, H.F., Chung, G.K.W.K., \&Herl, H.E. (1999).Computer-based collaborative knowledge mapping to measure team processes and team outcomes (No. 502). Los Angeles: University of California, National Center for Research on Evaluation, Standards, and Student Teaching.

Pankratius, W.J. (1990). Building an organized knowledge base: Concept mapping and achievement in secondary school physics.Journal Research in Scientific Teaching 27(4), 315-3. doi:10.1002/tea.3660270404, http://dx.doi.org/10.1002/tea.3660270404.

Pishghadam, R., \& Ghanizadeh, A. (2006). On the impact of concept mapping as a pre-writing activity on EFL learners' writing ability. Iranian journal of applied linguistics 9(2),103-130.

Pishghadam, R., \& Modarresi, A. (2008). The construct validation and application of a questionnaire of attribution theory for foreign language learners. International Journal of Language Studies, 2, 299-324.

Reese, D. D. (2004). Assessment and concept map structure: Interaction between subscores and well-formed mental models. Paper presented at the 2004 meeting of the American Educational Research Association, San Diego.

Ruiz-Primo, M. A., \& Shavelson, R. J. (1996). Problems and issues in the use of concept maps in science assessment. Journal of Research in Science Teaching 33(6), 569-600. 
doi:10.1002/(SICI)1098-2736(199608)33:6<569::AID-TEA1>3.0.CO;2-M, http://dx.doi.org/10.1002/(SICI)1098-2736(199608)33:6<569::AID-TEA1>3.0.CO;2-M.

Ruiz-Primo, M.A. (2000). On the use of concept maps as an assessment tool in science: what we have learned so far? RevistaElectrónica de Investigación Educativa,2(1).Retrieved May2006from: http://redie.uabc.mx/vol2no1/contenido-ruizpri.html

Schau, C., \& Mattern, N. (1997). Use of map techniques in teaching applied statistics courses. American Statistician 51, pp. 171-175. doi:10.2307/2685413, http://dx.doi.org/10.2307/2685413.

Schau, C., Mattern, N., Zelik, M., Teague, K.W., \& Weber, R.J. (2001). Select- and- fill- in- concept map scores as a measure of students' connected understanding of science. Educational and Psychological Measurement 61(1), 136-158. doi:10.1177/00131640121971112, http://dx.doi.org/10.1177/00131640121971112.

Shavelson, R., Lang, H., \&Lewin, B. (1993). On concept maps as potential "authentic" assessments in science. Los Angeles, CA: National Center for Research on Evaluation, Standards, and Student Testing. (ERIC Document Reproduction Service No. ED 367691.

Spivey, N. N., \& Mellon, C. (1989). Constructing constructivism: reading research in the United States. Occasional paper, 12, 34-58.

Turns, J., Atman, C. J., \& Adams, R. (2000). Concept maps for engineering education: A cognitively motivated tool supporting varied assessment functions. IEEF transactions on education 43(2), 56-89.

Table 1.The profile of SAFI concept map test-taking strategies

\begin{tabular}{|c|c|c|}
\hline Coding scheme & Description & Instances \\
\hline 1. skimming & $\begin{array}{l}\text { Going through the text quickly to form } \\
\text { an overall rough impression }\end{array}$ & $\begin{array}{l}\text { I read the text quickly first to see what it is about. } \\
\text { The title "spider silk" doesn't give me a hint of } \\
\text { what the topic is about. So I first read the passage to } \\
\text { form a general idea of the topic. }\end{array}$ \\
\hline $\begin{array}{l}\text { 2. concept } \\
\text { identification }\end{array}$ & $\begin{array}{l}\text { Identifying the concepts specified in the } \\
\text { concept map and enclosed in boxes }\end{array}$ & $\begin{array}{l}\text { This square indicates that this portion is about } \\
\text { "sea-level rising". }\end{array}$ \\
\hline $\begin{array}{l}\text { 3. proposition } \\
\text { formation }\end{array}$ & $\begin{array}{l}\text { Linking two concepts in the concept map } \\
\text { via the linking phrases to form a } \\
\text { proposition }\end{array}$ & $\begin{array}{l}\text { I look at the box "spider silk" and I read "is" and the } \\
\text { box "extremely strong" as" spider silk is extremely } \\
\text { strong". }\end{array}$ \\
\hline $\begin{array}{l}\text { 4. proposition } \\
\text { synthesizing }\end{array}$ & $\begin{array}{l}\text { Linking the identified propositions in the } \\
\text { concept map to form a section of the text } \\
\text { and ultimately the whole text }\end{array}$ & $\begin{array}{l}\text { I read the map "In modern teaching approaches", } \\
\text { "materials", "are”, square 6," lead to “, square } 7 .\end{array}$ \\
\hline $\begin{array}{l}\text { 5. text structure } \\
\text { identification }\end{array}$ & $\begin{array}{l}\text { Identifying the relationship between } \\
\text { ideas expressed in the text via the } \\
\text { connecting lines of the concept map, } \\
\text { recognizing and conceptualizing the } \\
\text { organization of the text (cause-effect, } \\
\text { compare-contrast, classification, etc) by } \\
\text { referring to the concept map }\end{array}$ & $\begin{array}{l}\text { By reading the map, I realized that the text is about } \\
\text { the properties and application of spider silk, and } \\
\text { about how to synthesize it. }\end{array}$ \\
\hline 6. gist locating & $\begin{array}{l}\text { Identifying the main idea, distinguishing } \\
\text { between salient and subsidiary points by } \\
\text { matching the concepts expressed in } \\
\text { concept map, as the main points, with the } \\
\text { corresponding ideas in the text }\end{array}$ & $\begin{array}{l}\text { Squares } 4 \text { and } 5 \text { are about the causes and } \\
\text { consequences of sea-level falling. So I go to } \\
\text { paragraph } C \text { in the text that is about global } \\
\text { warming as the result of sea-level falling. }\end{array}$ \\
\hline $\begin{array}{l}\text { 7. redundant idea } \\
\text { skipping }\end{array}$ & $\begin{array}{l}\text { Disregarding the redundant or irrelevant } \\
\text { materials in the text by going through the }\end{array}$ & $\begin{array}{l}\text { The section (F) I'm reading (about how to measure } \\
\text { sea-level rising or falling) does not seem necessary }\end{array}$ \\
\hline
\end{tabular}




\begin{tabular}{|c|c|c|}
\hline & $\begin{array}{l}\text { concept map, on the ground that the } \\
\text { concepts and the relations designated in } \\
\text { the map are the foci of the text and the } \\
\text { questions }\end{array}$ & $\begin{array}{l}\text { in completing the map, since nothing has been } \\
\text { mentioned in the map. }\end{array}$ \\
\hline 8. inference-making & $\begin{array}{l}\text { Finding the answer of a question based } \\
\text { on meanings not directly stated in the } \\
\text { text }\end{array}$ & $\begin{array}{l}\text { Item } 10 \text { says that "the synthetic spider silk is a) at } \\
\text { laboratory stage b) sophisticated c) expensive". } \\
\text { On reading the section: "At DuPont's laboratories, } \\
\text { Dorsch is excited by the prospect of new } \\
\text { super-strong materials but he warns they are many } \\
\text { years away. We are at an early stage but theoretical } \\
\text { predictions are that we will wind up..........It } \\
\text { conveys that synthetic spider silk is still at } \\
\text { laboratory stage. So option (a) must be the correct } \\
\text { answer. Options (b) and (c) are only expressed as } \\
\text { far as extracting the protein from the mussel is } \\
\text { concerned, not spider silk. }\end{array}$ \\
\hline 9. back tracking & $\begin{array}{l}\text { Going back to the earlier portions for the } \\
\text { purpose of finding the answer }\end{array}$ & $\begin{array}{l}\text { According to item 6, there is still another cause for } \\
\text { sea-level rising. I must reread the previous } \\
\text { paragraphs to find a different reason for sea-level } \\
\text { rising. }\end{array}$ \\
\hline $\begin{array}{l}\text { 10. correct response } \\
\text { selection via other } \\
\text { alternatives }\end{array}$ & $\begin{array}{l}\text { Eliminating improbable distracters to } \\
\text { decide upon the correct response }\end{array}$ & $\begin{array}{l}\text { Item } 11 \text { asks "what does assessment in modern } \\
\text { teaching approaches evaluate?" the first option is } \\
\text { "memorized items". Elsewhere in the text, the } \\
\text { writer conveyed that current degree courses are } \\
\text { based on rote learning, so option (a) can't be the } \\
\text { answer. The last paragraph about assessment states } \\
\text { that" a deep learning approach would test a student's } \\
\text { ability to tackle unfamiliar, real-world problems". } \\
\text { So option c (familiar problems) is not correct, } \\
\text { either. The answer should be option b (authentic } \\
\text { issues), although I'm not sure about the meaning of } \\
\text { authentic. }\end{array}$ \\
\hline $\begin{array}{l}\text { 11. correct response } \\
\text { selection via clues in } \\
\text { other items }\end{array}$ & $\begin{array}{l}\text { Deciding upon the correct answer by } \\
\text { discarding the other options through the } \\
\text { clues in other items and the options of } \\
\text { other items }\end{array}$ & $\begin{array}{l}\text { In the text tapping oil resources was used with } \\
\text { tapping underground water. Since I chose "use of } \\
\text { underground water" as a reason for land sink and } \\
\text { sea-level rising, so "tapping oil resources" can't be a } \\
\text { correct response for item } 9 \text { (the reason of sea-level } \\
\text { falling). }\end{array}$ \\
\hline
\end{tabular}

Table 2. Descriptive statistic of criterion test in each group

\begin{tabular}{|c|c|c|c|c|c|}
\hline & N & Minimum & Maximum & Mean & Std. Deviation \\
\hline CM & 105 & 37 & 82 & 64 & 9.7 \\
\hline MC & 98 & 34 & 83 & 68 & 12.2 \\
\hline GS & 97 & 32 & 80 & 62 & 8.8 \\
\hline
\end{tabular}


Table 3. ANOVA on group differences

\begin{tabular}{|l|c|c|c|c|}
\hline Source & SS & DF & MS & F \\
\hline Between groups & 867.270 & 2 & 433.635 & \multirow{2}{*}{4.073} \\
Within groups & 3167.773 & 297 & 106.457 & \\
\hline
\end{tabular}

Table 4. Hierarchical classification of SAFI concept map strategies

\begin{tabular}{|l|l|c|c|}
\hline Category & \multicolumn{1}{|c|}{ Strategy } & Frequency & Total \\
\hline Lower-order & Skimming & 4 & \\
Strategies & Concept identification & 92 & 180 \\
& Backtracking & 84 & \\
\hline Higher-order & Proposition formation & 68 & \\
& Proposition synthesizing & 62 & \\
& Text structure identification & 22 & \\
& Gist locating & 20 & 337 \\
& Redundant idea skipping & 8 & \\
& Inference-making & 57 & \\
\hline Testwiseness & Correct response selection & 12 & \\
Strategies & via other alternatives & & \\
& Correct response selection & & \\
& via clues in other alternatives & 536 & \\
\hline Total & & & \\
\hline
\end{tabular}

Fill-in-the-Nodes

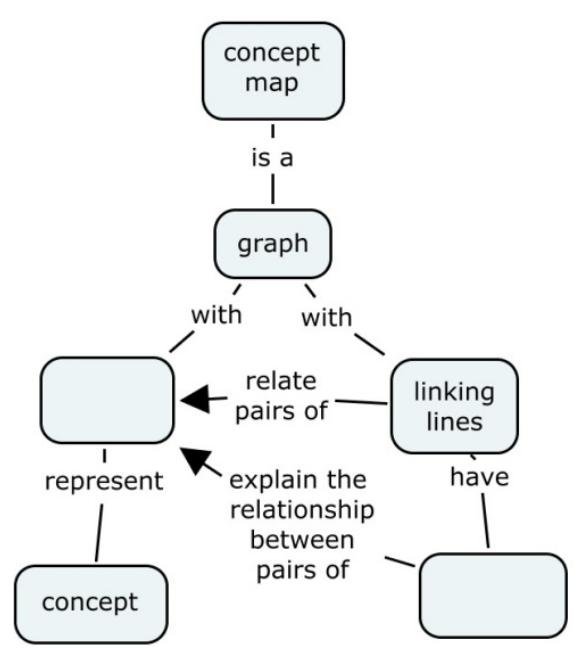

Fill-in-the-Lines

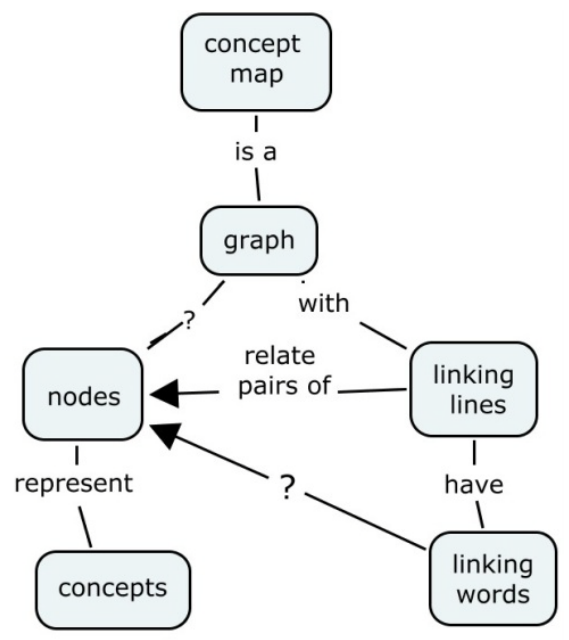

Figure 1. Examples of fill-in maps 


\section{Appendix}

\section{Questions1 - 10}

Read the whole passage first. Then decide which phrase best completes each of the numbered squares. Note: when completing the concept map, start from the central idea "spider silk", then proceed in the order of the numbered squares from 1-10.

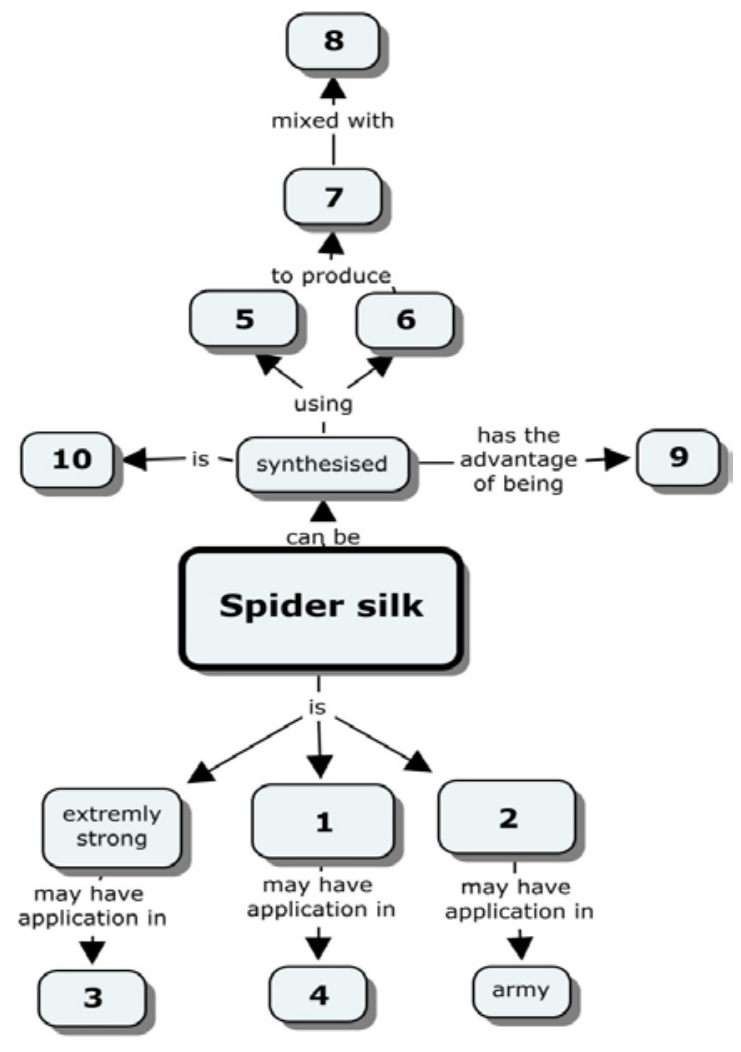

1

a) bio-material

b) highly elastic

c) capable of synthesizing

6
a) silk-producing glands
a) protein
b) spider DNA
b) silk
c) bacteria
c) solid fibers

7

8

a) water a) parachute industry

a) construction of suspension bridges

b) replacing nylon

b) yeast

c) water

5

a) egg

b) airplane industry

c) stopping a jumbo jet in flight
10

a) at laboratorystage

b) sophisticated

c) expensive 


\section{Questions 1-12}

Read the whole passage first. Then decide which phrase best completes each of the numbered

squares. Note: when completing the concept map, start from the central idea "Modern teaching approaches", then proceed in order of the numbered squares from 1-12.

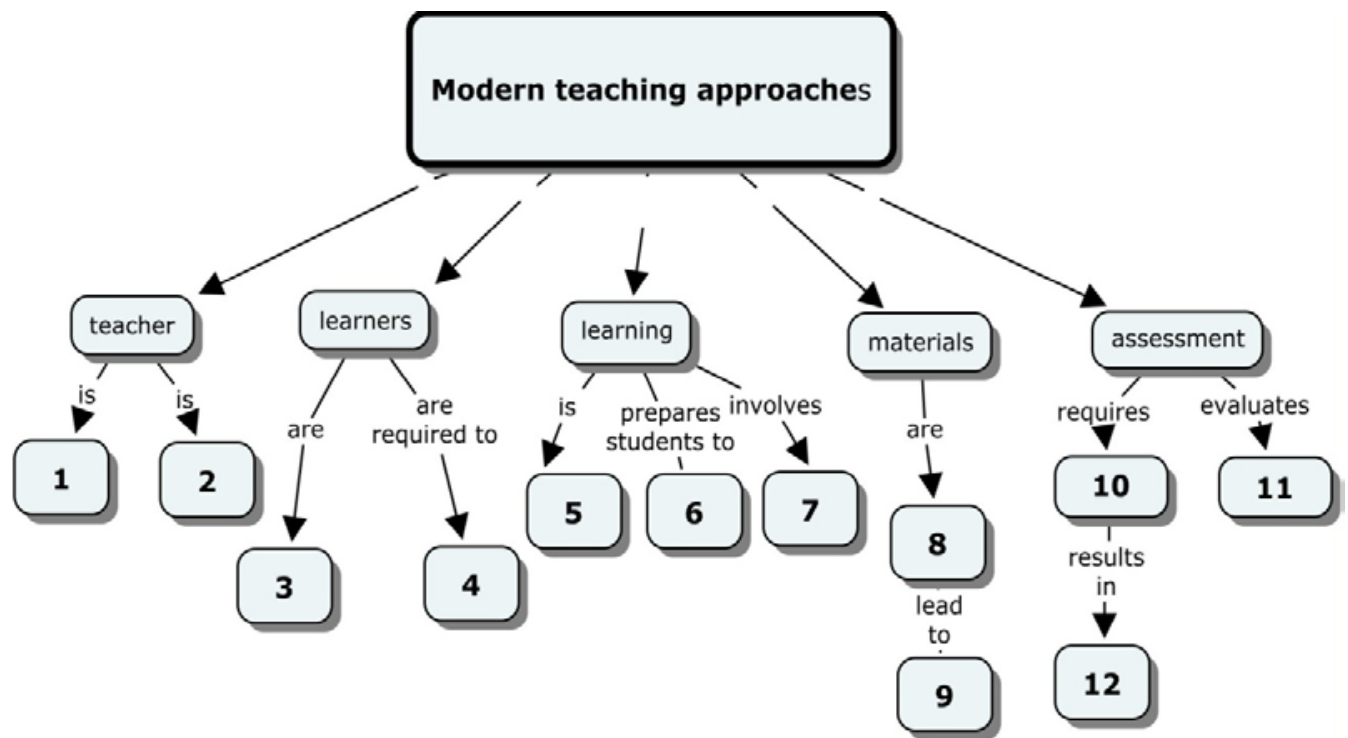
a) learning manager
b) information transmitter
b) attentive to educational content
c) problem solver
c) information transformer

6
a) content-centered
b) teacher-centered
c) student-centered

9
a) focus on teaching
b) biological
c) more learning activities
a) constructing a personal meaning
b) reiterating course materials
c) mastering content
a) fulfill job requirements
b) change jobs easily
c) create their own jobs

10

3

a) reactive

b) competitive

c) initiative-taker
4

a) transfer prior knowledge to new contexts

b) model the teacher

c) master the knowledge

\section{7}

a) modeling the teacher

b)creating new knowledge

c) rote-learning

\section{8}
a) text
b) content-based
c)audiovisual

11

a) memorized items

b) authentic issues

c) problems familiar
12

a) performing skills

b) complex abilities

c) learners' involvement 


\section{Questions 1-9}

Read the whole passage first. Then decide which phrase best completes each of the numbered squares. Note: when completing the concept map, start from the central idea "Global warming", then proceed in the order of the numbered squares from 1-9.

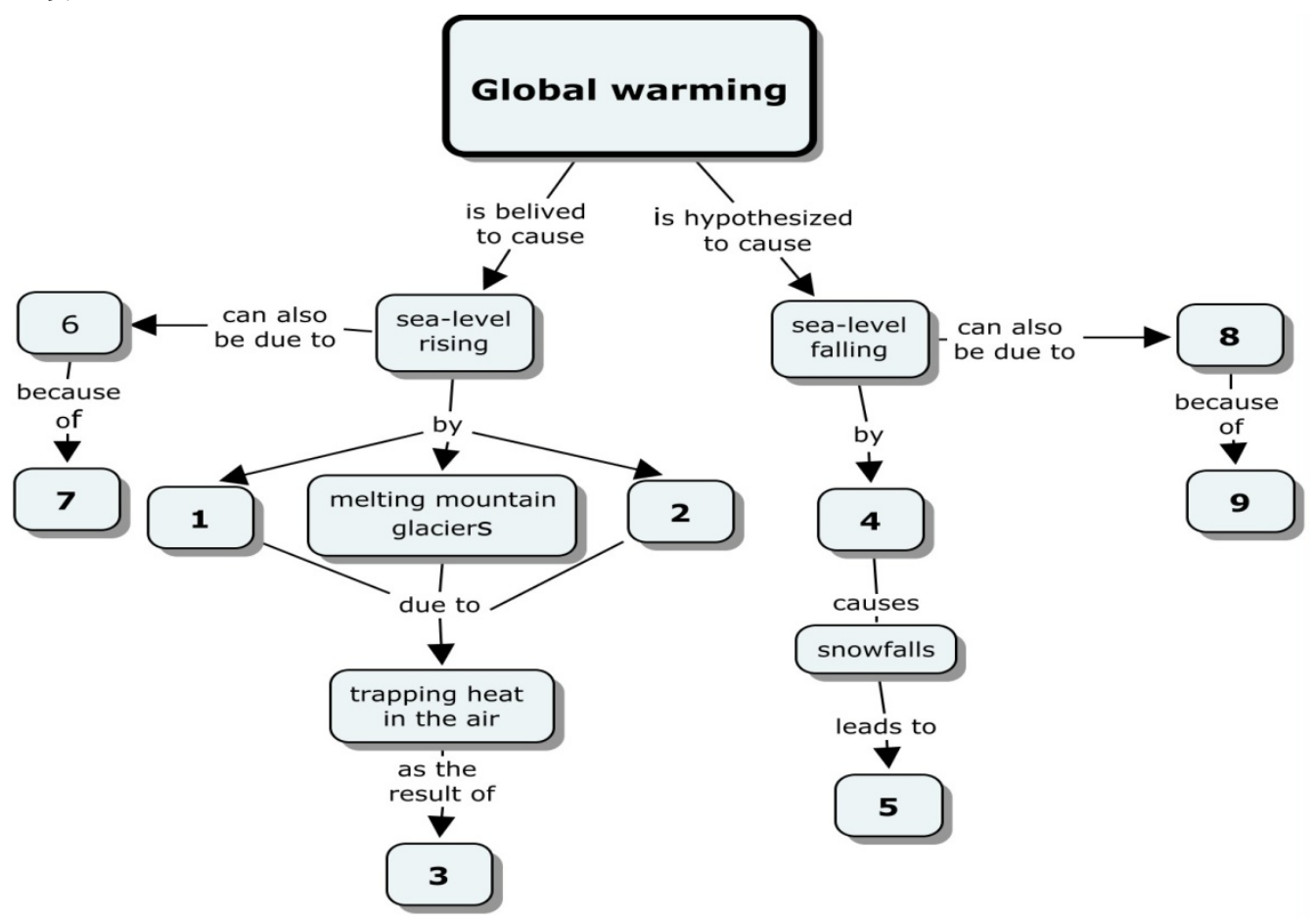

1
a) heating the atmosphere
b) expanding the sea water
c) creating more water

4
a) creating moisture
b) creating high tides
c) directing warm to Antarctica

7
a) heavy snow fall
b) use of ground water
c) land slide

2

3
a) melting Antarctica glaciers
a) green house warming
b) melting European's glaciers
b) releasing pollutants
c) increasing greenhouse heating
c) carbon dioxide increase
a) ice cap shrink
a) land sink
b) ice cap growth
b) land rise
c) global temperature increase
c) pressing the plates 